\title{
Artista às avessas: a ação cultural em diálogo com a educação
}

\section{Resumo}

Discute-se um exemplo de ação cultural cujas referências iniciais de concepção e realização se deram no campo da educação. Revelados pela ótica autobiográfica da artista, aquilo que em princípio aludia à tarefa e ao olhar do pedagogo, transforma-se em ação artística e cultural. Traremos um recorte pontual do espetáculo Coreológicas do Caleidos Cia. de Dança/SP para essa discussão, que traduz um artista às avessas: da pedagogia à arte.

Palavras-chave: dança, educação, dialogicidade

\section{Abstract}

This article discusses an example of cultural action which initial conception references were brought from the Education field. Revealed by the artist's point of view, what primarily could be seen as a pedagogue look upon art is transformed into artistic and cultural action. Examples for discussion will be drawn from the dance performance Choreologics by Caleidos dance co.

Keywords: dance, education, dialogue

\section{Educação em dança}

Apesar das transmutações de conceitos de tempo, espaço e corpo advindos das experiências pós-modernas no campo da dança; mesmo tendo a produção contemporânea de dança escancarado as fronteiras conceituais e de atuação de inúmeros artistas; a despeito da literatura produzida nos últimos 80 anos sobre processos de educação em dança ter varrido a reprodução mecânica de passos das salas de aula, em grande escala as práticas de educação na área de dança pouco foram alteradas no último século.

Pais e mães orgulham-se de ter seus filhos matriculados em escolas de dança com "modelo russo" (leia-se rígido e famoso), delegando a educação dos mesmos a uma equipe de treinadores. Professores de escolas públicas se desconsertam diante da ausência de "dicas" do formador para montagem de uma coreografia a ser apresentada pelos alunos no fim do ano. Gestores de educação aprovam programas oficiais

\footnotetext{
${ }^{1}$ Diretora/coreógrafa do Caleidos Cia. de Dança e do Instituto Caleidos, São Paulo/SP.
} 
que propõem sequências didáticas que garantirão passo a passo a atuação de seus professores na área de dança. Milhares de artistas da dança só conhecem e reconhecem essa arte repetindo-a, executando seus passos à exaustão.

A dança como sinônimo de repertório fixo e imutável e a educação como sinônimo de treino cristalizado e acrítico estão longe de serem totalmente banidos - ou até mesmo questionados - do meio social mais amplo. A crítica que se faz a esse binômio (repertório/treino) ainda está longe de alcançar em amplitude as academias de dança, os projetos sociais e governamentais, as escolas formais e até mesmo as companhias de dança. A expectativa do público, as crenças de professores e as práticas seculares de artistas na construção dessa dança treinamento repertório acirra um ciclo vicioso de difícil ruptura.

A cópia calada, sem compreensão, questionamento ou possibilidade de ressignificação tem garantido o discurso do aprimoramento meramente técnico, mecânico na manutenção de repertórios, sejam eles do coreógrafo da companhia, do artista convidado, da tradição, do professor de sala ou das sequências programadas pelos syllabus internacionais. A cópia mecânica de repertórios - que passa por exercícios técnicos rigorosos e nem sempre corretos - ainda é a prática mais comum e disseminada no território da educação em dança. A cópia de passos dos repertórios - de companhias consagradas às danças propostas pela mídia - ainda é o meio mais eficaz, contumaz e aceito pela grande maioria da população para se efetivar o "dançar".

As críticas que academicamente se fazem a esse tipo de ensino de dança não chegaram aos distantes rincões do país, às academias de bairro, às escolas formais, aos projetos sociais e governamentais a ponto de também modificar o conceito de dança dessa população. A dança continua sendo, para a grande maioria da população, uma sequência de passos, uma "coreografia", um repertório a ser perpetuado pelos artistas, portanto, por professores e alunos.

Desde 1988 tenho tentado entender esse quadro e propor outras formas de compreender o binômio dança/educação, focando a superação do descompasso entre o ensino de dança em suas diferentes instâncias e a produção contemporânea de dança. O grande vácuo entre educar e produzir arte não se estabelece somente nas academias privadas de dança (ou de ballet, como comumente são chamadas) dos rincões do Brasil - ele está também presente em renomadas companhias de dança contemporânea. 
As palavras dança e educação nos remetem, inicialmente, a dois campos semânticos geradores de no mínimo duas áreas de conhecimento, e a dois polos de atuação profissional aparentemente incomunicáveis. Reza o senso comum que dança/arte e educação são dois modos distintos de ser e estar em sociedade. Do mesmo modo, convenções sociais distinguem dois grupos de pessoas com interesses nem sempre mútuos e com práticas sociopolítico-culturais nem sempre alinhadas: de um lado, os professores, do outro, os artistas (Marques, 2010b).

Afastada do senso comum e das convenções sociais, compreendo dança e educação como campo híbrido, um binômio indissociável que se multiplica em inúmeros sentidos, entendimentos e ações (Marques, 1999, 2010ab). Nesse sentido, o campo da educação não é passível de redução às atividades escolares, às academias de dança, aos conservatórios ou aos projetos sociais em que a dança é ensinada. A educação não se restringe ao ensino.

Tendo como princípio que educar não se resume a ensinar, a educação tampouco não se restringe aos processos de ensino de aprendizagem articulados pela relação professor/aluno. Ao considerarmos dança e educação como um campo híbrido de conhecimento, estaremos também diante de todos os profissionais da dança envolvidos no cenário social de produção dessa arte (artistas, críticos, produtores, dramaturgos, iluminadores, curadores etc) atuando como educadores, não necessariamente como professores.

Na perspectiva de que, conforme coloca Paulo Freire, "educar é impregnar de sentido cada ato cotidiano" (apud Gadotti, 1998), artista e professor se aproximam de maneira significativa em suas ações sociopolítico-culturais: artistas também educam ao propor trabalhos de arte com o público, pois artistas impregnam e desdobram múltiplos sentidos com suas propostas artísticas. As relações entre artista/público, portanto, configuram-se com eminentemente educacionais, não necessariamente pedagógicas.

\section{Artista às avessas}

Sou formada em Pedagogia. Terminada a graduação, resolvi seguir os rumos da dança que já praticava desde os quatro anos de idade. A passagem pelo Laban Centre (hoje Trinity Laban), em Londres, fez-me compreender que meu caminho profissional não seria abandonar a educação, mas, sobretudo, caminhar no fio da navalha entre a dança e a educação. 
De volta ao Brasil, o início de minha carreira profissional deu-se na intersecção da prática pedagógica e da pesquisa acadêmica: nos anos de 1991-92 fui assessora na área de dança da gestão Paulo Freire na Secretaria Municipal de Educação de São Paulo, época em que desenvolvia também pesquisa de doutorado na Faculdade de Educação da USP. Clareava-se, portanto, uma perspectiva de continuidade de carreira mais voltada para a área de educação, embora atravessada pela dança.

Nessa época, deparei-me com a ausência da dança nas escolas formais e também com conceitos e práticas sobre arte (e dança) absolutamente incompatíveis e distantes daqueles propostos por Paulo Freire ou Rudolf Laban. Os contextos e conceitos de dança nas escolas públicas de São Paulo se opunham e ao mesmo tempo ignoravam aqueles estudados em pesquisa de doutorado - que se voltava para a arte contemporânea, para o estudo da "pós-modernidade" em dança e em educação. Da reprodução de passos ao laissez-faire, as escolas e professores com que trabalhei se encontravam repletas de exercícios e práticas pedagógicas, mas ausentes de arte.

Encontrei - e ainda encontro - nas escolas formais inúmeros professores não fazedores, não fruidores, não conhecedores de arte; professores até mesmo absolutamente "incuriosos" a respeito do sistema da arte. Encontrei alunos na mesma situação: executores de técnicas, de passos e de repertórios. A situação das práticas de ensino nas academias e companhias de dança, assim como de projetos sociais, não se diferenciava muito disso.

Reflexões, inquietações, questionamentos e críticas ao mundo estabelecido do ensino de dança e à situação em que a dança se encontrava nas escolas me motivaram a investigar e adentrar o universo da produção artística. Como "encher de arte" a escola? Seria a produção artística capaz de interferir de alguma forma no ciclo vicioso da dança como técnica que prepara para a execução de repertórios?

Considero-me uma artista às avessas: o chamamento para a educação (e também para o ensino) não veio em decorrência apenas de uma necessidade de sobrevivência, como para muitos artistas, nem mesmo como uma premência de continuidade de propostas artísticas a que a educação também serve. Sendo primeiramente pedagoga, deparei-me com uma realidade escolar totalmente desamparada sobre a dança e a arte em geral. Do meu ponto de vista, as relações entre arte e educação nas escolas formais estavam distorcidas, no mínimo anacrônicas. Aprofundando-me no que acreditava ser um processo de educação em dança, comecei minha carreira artística profissional propriamente dita. 
Em 1996, terminada minha pesquisa de doutorado, fundei o Caleidos Cia. de Dança, em São Paulo, capital. Antes disso, em 1993, havia criado o embrião do que seria o Caleidos Cia. tendo produzido o espetáculo Corpo Dócil, com a Bolsa Vitae de Artes. São, portanto, 18 anos trabalhando com o hibridismo entre a dança e a educação em situação de produção artística. Com a fundação da cia., algumas das questões levantadas durante a pesquisa de doutorado vieram novamente à tona ${ }^{2}$. Perguntas não mais explicitamente sobre as salas de aula, professores, escolas, mas sim voltadas para a produção artística propriamente dita, para uma ação que pudesse dialogar de forma significativa com o universo do ensino e aprendizagem de dança, sem se restringir a ele.

Tendo percebido que o universo da produção artística da dança muitas vezes é tão convencional quanto o observado nas escolas, ou seja, também pautados pelo binômio técnica/repertório, fechados, prontos a serem "cultuados", lancei-me o desafio de propor e experimentar processos de criação e fruição diferentes dos existentes: propus-me a pensar e a realizar processos/produtos atravessados por conceitos e vivências de tempo, espaço e corpo da contemporaneidade, que ao mesmo tempo (em uma mesma ação) dialogassem com conceitos e vivências de uma educação contemporânea.

Para que possam também educar dentro de um contexto de relações e vivências contemporâneas, como artistas poderiam experienciar outras formas de relação com o público que não as convencionais? Como o artista poderia abarcar as relações híbridas entre dança e educação sem, contudo, escolarizar a arte? Essa proposta "encheria de arte" a escola, os professores, a comunidade escolar? Poderia essa a proposta cênica (produção artística) contribuir para a transformação da escola cristalizada, embalsamada em vivências e conceitos de dança tão distantes das vivências contemporâneas de tempo, espaço e corpo de seus alunos?

Tendo em vista as relações híbridas entre educação e arte propostas pelo Caleidos Cia., vejo hoje que sua produção artística se configura como uma ação cultural, como uma maneira de "formar um público de posse de meios de acesso ao trabalho de criação, capaz de adotar uma posição crítica em relação aos produtos culturais e ao mundo em geral, assim como de participar ativamente na criação de bens simbólicos" (Pupo, 2009, p. 270). Vejo hoje que não foi o trabalho artístico que gerou uma ação

\footnotetext{
${ }^{2}$ As reflexões teóricas que antecedem essa produção estão em MARQUES, Isabel. A dança no contexto: uma proposta para a educação contemporânea. Tese (Doutorado) — Faculdade de Educação, Universidade de São Paulo, São Paulo, 1996
} 
educacional, mas sim uma postura educacional que se desdobrou em ação cultural, uma arte às avessas.

Discuto a seguir alguns dos conceitos educacionais que pautaram - e ainda pautam - o desenvolvimento das produções artísticas/ações culturais do Caleidos Cia. de Dança: a dialogicidade e a articulação de conhecimento.

\section{Dialogicidade}

"O diálogo é o encontro dos homens para a pronúncia do mundo"

(Freire, 1983, p. 79)

A ideia de diálogo como pro-núncia implica que diálogos são portadores de mensagens (do latim pro-nuntio-are), "estruturas ordenadas de signos que pode[m] propiciar a construção de significados” (Brazil, 2007 apud Marques, 2010a, p. 133). A pronúncia do mundo diz respeito a construir significados, de acordo com o mundo (ibid).

A impregnação de sentidos nos cotidianos, coloca Freire (1983), "não pode reduzir-se a um ato de depositar ideias de um sujeito no outro, nem tampouco de tornar-se simples troca de ideias a serem consumidas pelos permutantes” (p. 93). A educação como uma ação reflexiva que acarreta a pronúncia do mundo deve ser dialógica - e não bancária. Nessa linha de raciocínio, a dialogicidade como encontro aponta para que a pronúncia do mundo seja também um ato de criação, uma ação que gera e é gerada pela reflexão, sendo, portanto, também crítica (ibidem).

A proposta dialógica de Freire para a educação vai de encontro a tudo que presencio e vivo no mundo convencional da dança. No que tange ao ensino, ainda presenciamos práticas de alunos depósitos de coreografias que não foram criadas a partir de encontros; são frequentes a execução calada de passos que não tomam os dançantes como pronunciantes do mundo; propostas de ensino e aprendizagem que pressupõem a ingenuidade e agonizam diante da crítica são a tônica da maioria das salas de aula de dança.

No campo da produção artística, não são poucas as companhias de dança que ignoram sumariamente o conceito e a ação dialógicas, tanto no que tange às relações coreógrafo/intérprete quanto intérpretes/público. A voz única e silenciadora do diretor/ coreógrafo ainda impera na imposição de ideias, movimentos, concepções de arte que são apresentadas a um público mais amplo.

Diante do desafio/proposta de uma educação criadora, crítica e transformadora, a dialogicidade foi/é conceito atravessador das produções Caleidos Cia., especialmente 
de sua primeira proposta, Coreológicas. Para que uma produção de dança pudesse pronunciar o mundo, proporcionar encontros críticos, impregnar de sentidos - e transformar -, presumi que ela deveria ser dialógica. Já em 1996, perguntava-me como propor, dançando, esses processos dialógicos que rompessem com as convenções e hábitos de silenciamento provenientes de uma educação bancária que caracterizam o mundo instituído da dança.

O conceito freireano de dialogicidade se desdobrou artisticamente em compreender o papel dos artistas não como aqueles que apresentam coreografias, que mostram o mundo, mas sim como profissionais corresponsáveis pelo diálogo, pelo encontro, pela pronúncia do mundo. Compreender o papel dialógico do artista na cena da dança deu-se também ao compreendê-lo corresponsável pela construção de múltiplos sentidos na cena artística.

Diante desta perspectiva, desde 1993 trabalho com o conceito de artista/docente para compreender outras possibilidades de atuação de artistas que educam - e também de professores que produzem arte. O artista/docente, proponho, "é aquele que, não abandonando suas possibilidades de criar, interpretar, dirigir, tem também como função e busca explícita a educação em seu sentido mais amplo" (Marques, 1999, p. 112). Não mais distante e distanciado do público, o artista/docente "passa a ser a fonte do conhecimento [...] e não somente uma ponte entre o [público] e o mundo da arte" (ibidem, p. 113).

Para cunhar essa proposta, aproximei-me dos conceitos de "artista propositor" desenvolvidos por Lygia Clark e das propostas artísticas de Helio Oiticica. Com isso, entendi o papel do artista como aquele que compreende o público também de maneira distinta: some a perspectiva de espectadores passivos, distantes, contemplativos. Diante das proposições artísticas, o público passa a ser o realizador daquilo que os projetos anunciam (Favaretto, 1985). A arte contemporânea pressupõe um público que seja articulado, informado, sensível às proposições dos artistas; o público tende a ser incorporado aos trabalhos que não mais "mostram o mundo" e sim balizam sua construção (Lebrun, 1983).

Em 1993, trabalhei de forma embrionária com esses conceitos na produção do espetáculo de dança Corpo Dócil, compartilhado com alunos do Ensino Médio da cidade de São Paulo. Percebi que o conceito de "artista propositor" não dava conta do que acreditava em termos de educação: buscava um artista propositor consciente de sua função educacional, um artista propositor educador, ou o artista/docente. 
O artista/docente não se configura como um professor que dança, tampouco como um artista que ensina. $\mathrm{O}$ artista/docente é aquele que, numa mesma proposta, dança e educa: educa dançando e dança educando (Marques, 1999). O artista/docente constitui-se no hibridismo, assim como a dança e a educação. $O$ desafio do artista/ docente em cena é compreender que, ao dançar, não mostra, propõe; não apresenta, convida; não dança para, dança com o público; não ensina, educa.

Foi-se consolidando ao longo dos anos, nas diferentes produções de Coreológicas ${ }^{3}$ do Caleidos Cia., a intenção do artista em dançar consciente de que, na proposta artística em si, propunha diálogos múltiplos, convidava a si mesmo e ao público a dançar várias possibilidades de todos, para que no encontro pronunciem o mundo. Essa concepção vem de encontro à formação, acadêmica ou não, da maioria dos artistas da dança que não veem, no público, seus interlocutores e sim seus depositários. A produção de trabalhos que têm como pressuposto o conceito de artista/ docente exige um contínuo trabalho de formação dos intérpretes da companhia. Não tratarei desse assunto neste artigo.

O conceito de artista/docente implica, necessariamente, uma ruptura com os conceitos convencionais de processos coreográficos, tanto os implícitos no ato da criação quanto no compartilhamento da dança com o público. Certifiquei-me de que, para estabelecer diálogos que permitam encontros e pronunciem o mundo e que, ao mesmo tempo, proponham a construção de sentidos, a concepção convencional de "espetáculo" (evento espetacular) também deveria sofrer rupturas, transformações.

A meu ver, esse é um primeiro passo para que uma proposta educacional (não pedagógica) se compreenda no universo da ação cultural: as estruturas coreográficas (de cena de um modo geral) devem ser repensadas, os processos de criação devem ser revistos, as relações entre diretor/coreógrafo e intérpretes deve ser ressignificada para que a ação do artista não seja pedagógica, mas sim artística, artístico/educativa.

As produções de Coreológicas, desde seu início em 1996, são proposições interativas que jogam abertamente com os signos da linguagem da dança. No encontro entre interação, ludicidade e signos da linguagem, as propostas de Coreológicas foram/ estão sendo construídas em prol de um diálogo profícuo entre a dança e a educação. Vejamos esses três componentes do ponto de vista da dialogicidade/ação cultural.

${ }^{3}$ O Caleidos Cia. de Dança produziu, desde 1996, sete versões diferentes de Coreológicas: Coreológicas I, II, III, IV, V, Brasil-Finland e Ludus. Em 2008, foi produzido também o Coreológicas-Recife, com Acupe Grupo de Dança, de Recife. 
1) A interatividade propõe em sua etimologia uma atividade, uma ação "entre". Por essa razão, distingo o conceito de interatividade do de participação. Participação não implica, necessariamente, diálogo, é simplesmente uma parte da/na ação. Já a interatividade, é um convite para estar entre pelo menos duas coisas, para dialogar. Em Coreológicas, estabelece-se um diálogo coreográfico que gera relações significativas entre intérpretes, entre intérpretes e o público e entre o público consigo mesmo. A interatividade proposta pelo Caleidos Cia. pressupõe ações criativas do público que dialoga corporalmente com os artistas: o público completa e complementa a proposta coreográfica, reconstruindo e ressignificando a cena inicial da dança proposta.

A interatividade proposta em Coreológicas não se dá somente no momento em que o público "entra na cena" para dançar com os artistas, a interatividade faz parte integral da tessitura dos fios da composição coreográfica propriamente dita: a coreografia de Coreológicas se desenha atravessada pela interatividade, incorporando-a. Nessa produção artística, a coreografia é vista como um texto aberto que se articula a partir de signos da linguagem cuidadosamente escolhidos, escolhidos para que gerem diálogos e múltiplos sentidos quando dançadas na presença do público.

De fato, Coreológicas incorpora a ideia de que "a cena [teatral, da dança] é constituída por uma complexa articulação entre diferentes sistemas de signos que não têm sentido absoluto em si mesmos, mas só adquirem significado uns em relação aos outros" (Pupo, 2001, p. 182). A construção de redes de relações significativas entre os signos que constróem as coreografias de Coreológicas é intencionalmente dialógica e interativa, implica outra atitude diante da cena que, por sua vez, gera diálogos entre intérpretes e público.

2) A interatividade proposta em Coreológicas assume o caráter de ação cultural à medida que se propõe de forma lúdica, estabelecendo jogos entre os signos da linguagem da dança (proposições coreográficas) que, por sua vez, geram e são gerados com a interlocução do público presente. A ludicidade que se estabelece em cena, de certa forma análoga a do jogo teatral, "visa a fazer com que participantes de qualquer idade [gênero, biotipo, cultura corporal] adquiram consciência sobre a significação [da dança] e possam, através [dela], emitir um discurso sobre o mundo" (Pupo, 2001, p. 182). A interatividade lúdica de Coreológicas, proposta por artistas/docentes cria redes de relações, e as relações são sempre transformadoras (Freire, 1982). 
3) Coreológicas vem de "Coreologia", termo cunhado por Rudolf Laban para compreender a "lógica da dança," "a ordem oculta da dança," "as leis da dança." Laban colocava que o conhecimento da lógica da dança é um pré-requisito para se tornar um criador de cultura (Doerr, 2008). Os estudos coreológicos são vistos hoje como um "estudo das regras escondidas no movimento que o fazem expressivo e funcional, e não arbitrário ou sem sentido" (Preston-Dunlop, 1998, p. 276-77). Estudar, conhecer, dançar atravessados conscientemente pelos estudos coreológicos, portanto, nos possibilita compreender os jogos de linguagem, criar redes de relações e, enfim, sermos leitores críticos da dança/mundo (Marques, 2010a).

As produções artísticas de Coreológicas do Caleidos Cia. trabalham diretamente com os signos da linguagem da dança: proposições são criadas tendo a articulação dos signos como instigadores de processos de improvisação e de composição. Ao serem dançadas, as proposições Coreológicas estabelecem diálogos entre artista e público de forma interativa e lúdica, culminando, em última instância, na apropriação (tornar próprio) dos signos da dança por parte do público. Com isso, artistas e públicos são, a cada compartilhamento, cocriadores da dança, cocriadores do mundo.

\section{Articulação do conhecimento}

Uma segunda premissa educacional que foi tomada como referencial para a criação dos espetáculos interativos e lúdicos do Caleidos Cia. foi a proposta de articulação do conhecimento. Diferentemente dos cotidianos das salas de aula de dança nas diversas situações sociais - e também em companhias de dança - em que o conhecimento é fragmentado, isolado, não relacional, as diferentes proposições cênicas do Caleidos Cia. incorporam e corporeificam artística e esteticamente o conhecimento conectado (Stinson, 1998) e a rede de relações entre os diferentes conteúdos da dança - e desses conteúdos com a sociedade (Marques, 2010a).

A articulação de conhecimento, que vem ao encontro de uma prática pedagógica crítica e transformadora, foi/é também geradora de textos e proposições coreográficas de Coreológicas, proposições essas capazes de criar condições para que as pessoas criem suas próprias redes de sentidos.

As redes de relações propostas por Ana Mae Barbosa (2010 etc.), e que foram sintetizadas na Proposta Triangular para o Ensino da Arte na década de 1980, constituíram-se como importantes referenciais do pensamento educacional na concepção e produção artística de Coreológicas ao longo dos anos. 
Tendo proposto que o ensino de Arte não pode prescindir da leitura da obra (apreciação crítica), nem de sua contextualização histórica, Barbosa incorpora ao fazer artístico, o mais presente nas práticas pedagógicas de Arte, duas novas dimensões de suma importância nos processos de ensino e aprendizagem das diferentes linguagens artísticas: a apreciação e a contextualização. Articulados, fazer, apreciar/ ler, contextualizar compõem uma rede de saberes imprescindíveis à construção de conhecimento na área de Arte.

À primeira articulação de conhecimento proposta por Barbosa (fazer/apreciar/ contextualizar), sugeri nos últimos anos de trabalho com a área de ensino de dança o acréscimo de mais duas faces: articular o conhecimento específico de arte (fazer, apreciar e contextualizar) ao conhecimento que se tem de si mesmo/dos outros e ao conhecimento do mundo (Marques, 1999, 2010ac etc.). Arte/ensino/sociedade formam um tripé articulado de relações não hierárquicas que constituíram a proposta metodológica da Dança no Contexto (Marques, 1999, 2010a).

As redes de relações articuladas de conhecimento atravessam as propostas artísticas do Caleidos Cia. desde sua fundação. O princípio pedagógico de articulação de conhecimento constituíram/constituem os processos de concepção e de produção artísticas da cia. de maneiras variadas, sendo sempre, no entanto, parâmetros de construção e de leitura dos trabalhos realizados.

Tomando como exemplo Coreológicas, o tripé sugerido por Barbosa se dá claramente na proposição dos artistas em cena: as "mini coreografias" (proposições cênicas de no máximo 8 minutos) são um convite à apreciação/leitura para que, posteriormente, o público interaja corporalmente com os artistas. A apreciação/leitura permite que o fazer/interagir tenha uma proposta, mesmo que aberta. Tendo proposta, o conhecimento pode ser articulado significativamente. No jogo contínuo que se estabelece entre apreciação e interação, signos são articulados, sentidos são construídos a partir do trabalho artístico e não dissociados dele.

Em Coreológicas, a interação corporal crítica só se processa na leitura afinada do que é proposto pelos artistas em termos de articulação de signos pela composição coreográfica. Desse modo, corpos são convidados a criar de acordo com parâmetros artísticos: convidados a articular conhecimento e não meramente a "soltar a alma" desconectados da cena proposta. Diante disso, o público é também convidado a adotar posições relacionadas às propostas artísticas, possibilitando, assim, diálogos, e não monólogos coletivos. 
$\mathrm{Na}$ possibilidade de diálogos que articulam conhecimentos, artistas e público podem recriar as cenas propostas, educando-se. Essa possibilidade faz com que também ressignifiquem suas cenas cotidianas pessoais. A dialogicidade cênica articulada a redes de conhecimento atravessa outras cenas sociais, articuladas entre si, abrindo espaços para que as interações sociais também sejam transformadas.

\section{Referências bibliográficas}

BARBOSA, Ana Mae; CUNHA, Fernanda (Orgs). Abordagem triangular no ensino das artes e culturas visuais. São Paulo: Cortez Editora, 2010.

DOERR, Evelyn. The dancer of the crystal. Plymouth: The Scarecrow Press, 2008.

FAVARETTO, Celso. Arte contemporânea. In PACHECO, E. (Org.). Comunicação, educação e arte na cultura infanto-juvenil. São Paulo: Loyola, 1985, pp. 93-98.

FREIRE, Paulo. Educação e mudança. Rio de Janeiro: Paz e Terra, 1982.

Pedagogia do oprimido. Rio de Janeiro: Paz e Terra, 1983.

GADOTTI, Moacir. Programa de rádio "Paulo Freire, andarilho da utopia", parceria entre a Rádio Nederland e o Instituto Paulo Freire, 1998.

LEBRUN, Gérard. A mutação da obra de arte. In LEÃO, E. (Org.). Arte e filosofia. Rio de Janeiro: Funarte, 1983, pp. 21-31.

MARQUES, Isabel. Ensino de dança hoje: textos e contextos. São Paulo: Cortez Editora, 1999.

Linguagem da dança: arte e ensino. São Paulo: Digitexto, 2010a.

Dança-educação ou dança e educação? In MARINHO, N.; TOMAZZONI, A. e WOSNIAK, C. (Orgs.). Seminários de Dança 3. Blumenau: Nova Letra Gráfica e Editora, 2010b, pp. 25-37.

De tripé em tripé: o caleidoscópio do ensino de dança. In BARBOSA, A. M.; CUNHA, F. (Orgs.). Abordagem triangular no ensino das artes e culturas visuais. São Paulo: Cortez Editora, 2010c, pp. 52-63.

PRESTON-DUNLOP, Valerie. Looking at dances: a choreological perspective on choreography. London: Verve Publishing, 1998.

PUPO, Maria Lúcia. O lúdico e a construção do sentido. Sala Preta. ECA-USP, v. 1, pp. 18187, 2001.

Para alimentar o desejo de teatro. Sala Preta. ECA-USP, v. 9, pp. 269-78, 2009.

STINSON, Susan. Seeking a feminist pedagogy for children's dance. In SHAPIRO, S. (Ed.). Dance, power and difference. Champaign: Human Kinetics, 1998, pp. 23-48. 